\title{
Haemodynamic effects of hydrallazine and of hydrallazine plus glyceryl trinitrate paste in heart failure
}

\author{
J. MEHTA, C. J. PEPINE, AND C. R. CONTI
}

From the Cardiovascular Division, VA Hospital and $\mathcal{F H M ~ H e a l t h ~ C e n t e r , ~ U n i v e r s i t y ~ o f ~ F l o r i d a , ~ C o l l e g e ~ o f ~}$ Medicine, Gainesville, Florida, U.S.A.

SUMMARY In a study designed to investigate potential non-parenteral treatment for chronic heart failure, hydrallazine, 225 to $300 \mathrm{mg}$ per day, was given orally to 9 patients. There was no significant change in heart rate or mean arterial pressure as cardiac output increased. Left ventricular stroke work increased significantly and pulmonary artery wedge pressure fell. Systemic and pulmonary vascular resistances fell. With the addition of 2 per cent glyceryl trinitrate paste, there was a further decline in mean pulmonary arterial and wedge pressures, without a significant change in heart rate, arterial pressure, cardiac output, or systemic or pulmonary vascular resistance. There were no untoward effects from either form of treatment. All patients reported relief of shortness of breath and other symptoms related to ventricular dysfunction. This study supports the suggestion that oral hydrallazine is effective in increasing cardiac output and decreasing pulmonary congestion. Furthermore, the addition of topical glyceryl trinitrate provides a greater reduction of pulmonary pressures, probably through its predominant venodilator action. In some selected patients with heart failure, oral hydrallazine and topical glyceryl trinitrate in combination produce beneficial clinical and haemodynamic effects, probably through afterload and preload reduction, respectively.

Decrease in left ventricular afterload in heart failure has been shown to improve left ventricular function by increasing forward stroke volume and decreasing left ventricular filling pressure (Franciosa et al., 1972; Chatteriee et al., 1973; Guiha et al., 1974). This beneficial effect can be seen in various clinical circumstances, including coronary artery disease (Franciosa et al., 1972; Chatterjee et al., 1973), mitral and aortic regurgitation (Chatterjee et al., 1973; Bolen and Alderman, 1976), and hypertensive heart disease (Majid et al., 1971). Reduction of preload, on the other hand, lowers left ventricular filling pressure but does not consistently result in improved stroke volume (Franciosa et al., 1974; Mantle et al., 1976). In some patients, the decrease in preload resulting from treatment with potent diuretics like frusemide or venodilator agents like nitrates may result in a fall in cardiac output (Mehta, 1977).

Intravenous nitroprusside produces a rapid increase in cardiac output and a fall in left ventricular filling pressure in patients with heart failure;

Received for publication 6 September 1977. these beneficial effects are reversed when the drug is withdrawn. Because nitroprusside must be given parenterally, its usefulness is limited. Hydrallazine is an oral agent with predominant action as an arteriolar dilator (Stunkard et al., 1954; Rowe et al., 1955; Åblad, 1963). Initial studies have shown it to be effective in heart failure (Chatterjee et al., 1976; Franciosa et al., 1977), though the fall in pulmonary arterial and left ventricular filling pressures is only slight to moderate (Chatterjee et al., 1976). Oral or topical administration of long-acting nitrates provides a means of decreasing preload as a result of their venodilator effect (Cohn, 1973; Mehta, 1977). The purpose of this study was to evaluate further the haemodynamic effects of oral hydrallazine and its combination with glyceryl trinitrate paste in patients with heart failure.

\section{Methods}

PATIENT SELECTION

Nine men (age 42 to 65 years) with persistent heart failure, despite treatment with digitalis, diuretics, and salt restriction, were studied after giving in- 
formed consent. The duration of heart failure ranged from 1 to 6 years. The diagnosis of heart failure was made on clinical, radiological, and haemodynamic criteria. Eight of these patients had heart failure secondary to coronary heart disease, though none had angina at the time of study. One patient had primary myocardial disease. Clinical and angiographic evidence of left ventricular aneurysm was present in 2 patients. Eight patients had angiocardiographically proven areas of segmental asynergy resulting from coronary artery disease, and 1 had diffuse hypokinesia. Atrial fibrillation was present in 1 patient.

\section{HAEMODYNAMIC STUDIES}

All studies were performed in a special study room in the coronary care unit. All drugs, including digitalis, diuretics, and antiarrhythmic agents were continued. A triple lumen flow-directed catheter was placed in the pulmonary artery via an antecubital vein. A short 'teflon' catheter was inserted percutaneously into the brachial artery to measure systemic arterial pressure. Aortic and pulmonary arterial pressures (systolic, diastolic, and mean) and mean pulmonary artery wedge pressure were recorded on a VR-6 recorder (Electronics for Medicine, White Plains, N.Y.) using P231A Statham strain gauges. Occluded pulmonary arterial pressure by balloon inflation correlated closely with pulmonary arterial diastolic pressure in all patients. Thus, either pressure was used as an index of left ventricular filling pressure. All pressure measurements were recorded with zero at the midchest level. Heart rate was recorded by continuous electrocardiographic monitoring. Measurements of cardiac output were obtained in triplicate by the thermodilution technique (Ganz and Swan, 1972) using a thermodilution computer (Edwards Laboratory, Santa Ana, Calif.).

\section{CALCULATIONS}

The following calculations were made:

$$
\begin{aligned}
& \text { SV }=\mathrm{CO} / \mathrm{HR}(\mathrm{ml}) \\
& \text { LVSW }=\mathrm{SV} \times(\mathrm{MAP}-\mathrm{PAWP}) \times 0.0136(\mathrm{~g} \mathrm{~m}) \\
& \text { SVR }=\text { MAP } / \text { CO (units) } \\
& \text { PVR }=\mathrm{PAM}-\mathrm{PAWP} / \mathrm{CO} \text { (units) }
\end{aligned}
$$

Abbreviations: SV, stroke volume; $\mathrm{CO}$, cardiac output; HR, heart rate; LVSW, left ventricular stroke work; MAP, mean arterial pressure; PAWP, pulmonary artery wedge pressure; SVR, systemic vascular resistance; PVR, pulmonary vascular resistance; PAM, mean pulmonary artery pressure.

All values were expressed as mean \pm SEM. Student's $t$ test was used for statistical analysis.

\section{PROCEDURE}

Several control measurements were made after the subjects had been in bed for at least 3 hours. Patients were then given oral hydrallazine 75 to $100 \mathrm{mg}$ every 8 hours. Haemodynamic measurements were made every 1 hour for the first 3 hours and subsequently every 3 hours for up to 72 hours. In 1 patient, the dose of hydrallazine was reduced to $75 \mathrm{mg}$ every 8 hours because of frequent headaches not related to the time of drug administration, hypotension, or tachycardia. At the end of the 72-hour period, 8 patients had 1 inch of 2 per cent glyceryl trinitrate paste applied to the skin; aortic, pulmonary artery and wedge pressures, heart rate,

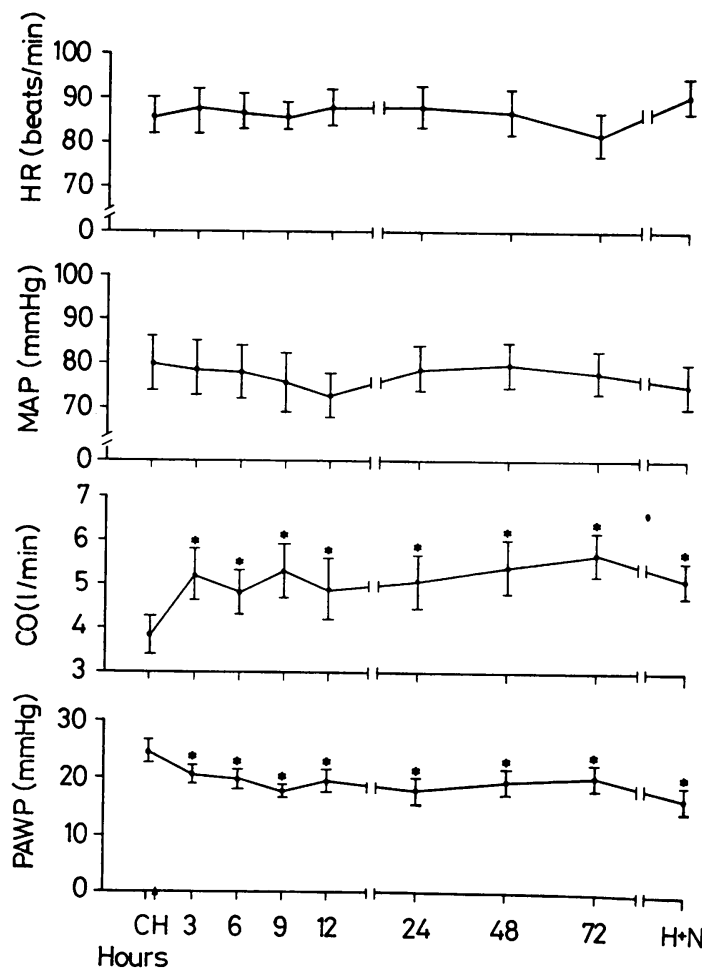

Fig. 1 Haemodynamic responses to hydrallazine in 9 patients with heart failure. Heart rate and mean arterial pressure were unchanged, cardiac output was increased, and pulmonary artery wedge pressure fell. Glyceryl trinitrate ointment application further lowered pulmonary artery wedge pressure, with no change in heart rate, mean arterial pressure, or cardiac output. $H R$, heart rate; $M A P$, mean arterial pressure; $C O$, cardiac output; $P A W P$, mean pulmonary artery wedge pressure; $C$, control; $H$, oral hydrallazine started; $\mathrm{H}+\mathrm{N}$, oral hydrallazine and glyceryl trinitrate paste combination. ${ }^{*} P<0.01$. 

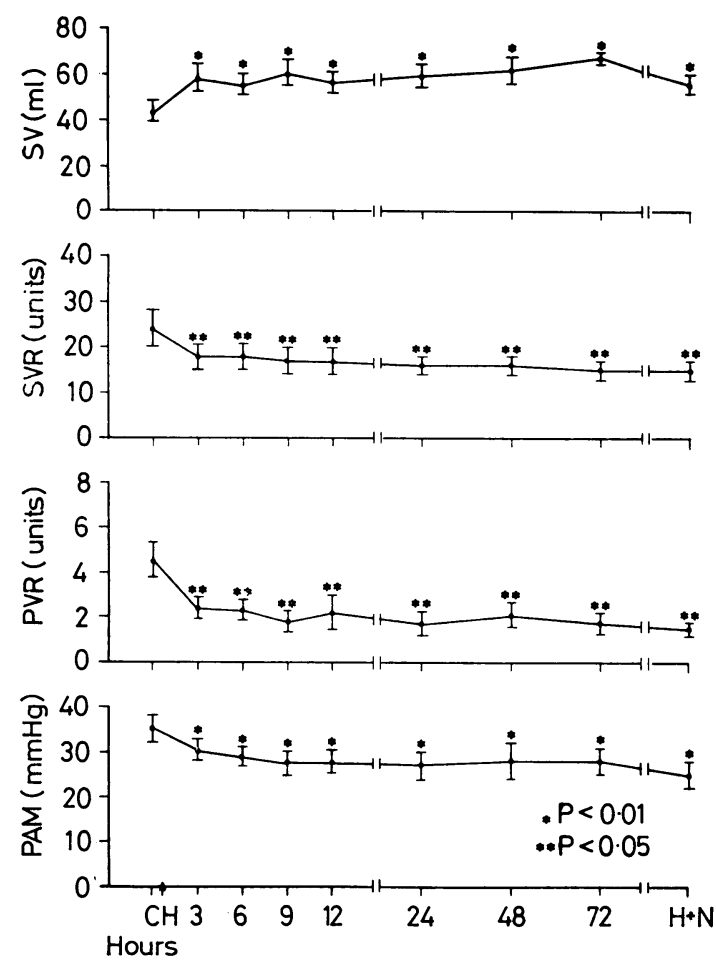

Fig. 2 Haemodynamic responses to hydrallazine therapy in 9 patients with heart failure. Stroke volume increased, and there was a fall in systemic and pulmonary vascular resistance and mean pulmonary arterial pressure. This response was evident at 3 hours and persisted for 72 hours. Glyceryl trinitrate ointment application further lowered the systemic and pulmonary vascular resistances and mean pulmonary arterial pressure. Abbreviations: $S V$, stroke volume; SVR, systemic vascular resistance; $P V R$, pulmonary vascular resistance; $P A M$, mean pulmonary arterial pressure.

and cardiac output were recorded hourly for a further 3 hour period.

\section{Results}

HYDRALLAZINE TREATMENT

Significant haemodynamic changes first appeared 3 hours after oral administration of hydrallazine and persisted for as long as the drug was administered (Fig. 1 and 2). Seven of the nine patients felt less fatigued and 6 were less short of breath.

Heart rate did not significantly change in any patient. Mean heart rate was $87 \pm 4$ beats per minute, compared with $86 \pm 4$ beats per minute in the control period. Mean arterial pressure was also unchanged ( $79 \pm 4$ vs. $80 \pm 6 \mathrm{mmHg}$ ). Cardiac output rose significantly at 3 hours and remained higher throughout the study period. The mean increase in cardiac output was 41 per cent $(5.42 \pm$ 0.4 vs. $3.85 \pm 0.51 / \mathrm{min}, P<0.01)$. Though mean cardiac output was higher at 3 hours after hydrallazine administration, the peak response was not observed until 48 or 72 hours in some patients. Stroke volume increased by 38 per cent ( $62 \pm 4$ vs. $45 \pm 5 \mathrm{ml} /$ beat, $P<0.01$ ).

A significant fall in mean pulmonary arterial pressure was observed, from $35 \pm 4$ to $28 \pm 3$ $\mathrm{mmHg}(P<0.01)$, and pulmonary artery wedge pressure also fell, from $24 \pm 2$ to $19 \pm 2 \mathrm{mmHg}$ $(\mathbf{P}<0.01)$. Pulmonary artery wedge pressure fell in every patient, and mean pulmonary arterial pressure fell in all but 2 patients (Table).

Resistance in both systemic and pulmonary vascular beds decreased. Systemic vascular resistance fell 36 per cent from $24 \cdot 0 \pm 3 \cdot 8$ to $15 \cdot 4 \pm 1 \cdot 5$ units $(P<0.05)$ and pulmonary vascular resistance fell 54 per cent from $3.3 \pm 0.9$ to $1.5 \pm 0.3$ units $(P<0.05)$. Systemic vascular resistance fell in all 9 patients; though pulmonary vascular resistance fell in 7, it rose in 1 (case 5) and was unchanged in another (case 7) (Table). Left ventricular stroke work increased 44 per cent from $35.4 \pm 7.2$ to $50.9 \pm 5.7 \mathrm{~g} \mathrm{~m}(\mathrm{P}<0.05)$.

\section{HYDRALLAZINE AND GLYCERYL TRINITRATE} TREATMENT

Addition of 2 per cent glyceryl trinitrate paste produced some haemodynamic alteration, but there was no further change in the patient's symptoms. There were no hypotensive or other unwanted symptoms.

Heart rate and arterial pressure were unchanged. Cardiac output fell slightly but not significantly from $5.42 \pm 0.4$ to $5 \cdot 10 \pm 0.41 / \mathrm{min}$, but was still significantly higher than the control value. Stroke volume fell significantly from $62 \pm 4$ to $56 \pm 4$ $\mathrm{ml} /$ beat $(P<0.05)$, but again was higher than the control value $(P<0.01)$. Mean pulmonary arterial pressure fell further, from $28 \pm 3$ to $25 \pm 3 \mathrm{mmHg}$ $(P<0.05)$. A similar change in mean pulmonary artery wedge pressure (19 \pm 2 vs. $16 \pm 2 \mathrm{mmHg}$, $P<0.05)$ was also observed. There was no further change in systemic or pulmonary vascular resistance or left ventricular stroke work. Systemic and pulmonary resistances were still lower and left ventricular stroke work higher than control values (Table).

\section{COMPLICATIONS}

No patient in this study developed hypotension or tachycardia. Two patients had nausea initially but it gradually disappeared. Severe headache responsive to paracetamol developed in one patient and in him hydrallazine dose was decreased to $75 \mathrm{mg}$ every 8 hours; even after stopping hydrallazine, headache 
Table Haemodynamic response to hydrallazine glyceryl trinitrate combination in heart failure

\begin{tabular}{|c|c|c|c|c|c|c|c|c|c|c|c|c|}
\hline \multirow[t]{2}{*}{ Case no. } & \multicolumn{3}{|c|}{$H R$ (beats/min) } & \multicolumn{3}{|c|}{$M A P(m m H g)$} & \multicolumn{3}{|c|}{$P A P(m m H g)$} & \multicolumn{3}{|c|}{$P A W P(m m H g)$} \\
\hline & $C$ & $H$ & $H+N$ & $C$ & $\boldsymbol{H}$ & $H+N$ & $C$ & $H$ & $H+N$ & $C$ & $H$ & $H+N$ \\
\hline 1 & 80 & 76 & 88 & 86 & 73 & 67 & 52 & 41 & 33 & 34 & 31 & 28 \\
\hline 2 & 90 & 96 & 98 & 66 & 65 & 65 & 41 & 31 & 32 & 22 & 18 & 21 \\
\hline 3 & 85 & 80 & 84 & 91 & 85 & 72 & 36 & 20 & 15 & 30 & 16 & 11 \\
\hline 4 & 64 & 72 & 68 & 101 & 93 & 93 & 33 & 24 & 20 & 23 & 16 & 12 \\
\hline 5 & 87 & 90 & 92 & 100 & 100 & 96 & 19 & 19 & 18 & 14 & 12 & 10 \\
\hline 6 & 75 & 78 & - & 50 & 87 & - & 41 & 30 & - & 32 & 25 & - \\
\hline 7 & 83 & 88 & 92 & 61 & 59 & 60 & 27 & 27 & 24 & 21 & 20 & 16 \\
\hline 8 & 106 & 101 & 109 & 73 & 78 & 74 & 45 & 40 & 38 & 25 & 23 & 20 \\
\hline 9 & 103 & 99 & 100 & 95 & 74 & 75 & 19 & 18 & 17 & 16 & 14 & 14 \\
\hline Mean & 86 & 87 & 91 & 80 & 79 & 75 & 35 & 28 & 25 & 24 & 19 & 16 \\
\hline \pm SEM & 4 & 4 & 4 & 6 & 4 & 5 & 4 & 3 & 3 & 2 & 2 & 2 \\
\hline $\begin{array}{l}\text { P value } \\
\text { Cvs } \\
\text { C vs } \mathbf{H}+\mathbf{N} \\
\text { Hvs } \mathbf{H}+\mathbf{N}\end{array}$ & \multicolumn{3}{|c|}{$\begin{array}{l}\text { NS } \\
\text { NS } \\
\text { NS }\end{array}$} & \multicolumn{3}{|c|}{$\begin{array}{l}\text { NS } \\
\text { NS } \\
\text { NS }\end{array}$} & \multicolumn{3}{|c|}{$\begin{array}{l}<0.01 \\
<0.01 \\
<0.05\end{array}$} & \multicolumn{3}{|c|}{$\begin{array}{l}<0.01 \\
<0.01 \\
<0.05\end{array}$} \\
\hline
\end{tabular}

Abbreviations: HR, heart rate; MAP, mean arterial pressure; PAP, mean pulmonary artery pressure; PAWP, mean pulmonary artery wedge pressure; CO, cardiac output; SV, stroke volume; SVR, systemic vascular resistance; PVR, pulmonary vascular resistance; LVSW, left ventricular stroke work

$\mathrm{C}$, control; $\mathbf{H}$, hydrallazine alone; $\mathbf{H}+\mathbf{N}$, hydrallazine glyceryl trinitrate combination.

persisted. One other patient developed constant mild headache though his aortic pressure was maintained and cardiac output increased. Atrial fibrillation with no change in ventricular rate developed in one patient, but normal rhythm returned spontaneously while he was still on hydrallazine.

\section{Discussion}

Our results confirm that hydrallazine increases cardiac output. The fall in left ventricular filling pressure, though small, is statistically significant. Pulmonary arterial pressure and pulmonary vascular resistance also fell in our patients. The increase in cardiac output in our patients is similar to that reported by others (Chatterjee et al., 1976; Franciosa et al., 1977) but the fall in pulmonary arterial and wedge pressures seen in our patients was not observed by other investigators (Chatterjee et al., 1976). This may be because of the higher dose of hydrallazine used in our study. Increased stroke volume and stroke work in association with a decrease in left ventricular filling pressure reflects improved left ventricular performance. Indeed, our patients reported a decrease in symptoms of left ventricular dysfunction.

Hydrallazine when used in normotensive or hypertensive individuals with normal cardiac output frequently causes reflex tachycardia (Moyer, 1953) consequent upon its dilator $\mathrm{effect}$ at arteriolar level (Franciosa et al., 1977; Moore-Jones and Peroy, 1966). However, our study shows that neither a fall in systemic arterial pressure nor tachycardia is a problem when hydrallazine is used in patients with heart failure. It is likely that increase in cardiac output is responsible for maintaining blood pressure and preventing reflex tachycardia.

The exact mechanism for the increase in cardiac output with hydrallazine administration is not known. The simplest explanation is that this is secondary to the fall in systemic vascular resistance, as is seen with other afterload reducing agents like nitroprusside (Franciosa et al., 1972; Chatterjee et al., 1973a; Guiha et al., 1974). Some investigators have, however, reported direct and indirect cardiostimulatory actions of hydrallazine (Koch-Weser, 1974; Khatri et al., 1977). Some of these cardiostimulatory actions of hydrallazine can be blocked by $\beta$-adrenergic blocking drugs (Khatri et al., 1977). Whatever the mechanism of action, it appears that hydrallazine administration significantly improves stroke volume and stroke work without fall in systemic pressure or increase in heart rate.

These haemodynamic effects of hydrallazine are similar to those of intravenous nitroprusside, except that the latter results in a greater fall in pulmonary arterial and wedge pressures probably because of its effect both on capacitance and resistance vessels (Miller et al., 1976), whereas hydrallazine appears to have its predominant effect on the resistance vessels (Franciosa et al., 1977). Addition of glyceryl trinitrate paste to hydrallazine therapy resulted in a further decrease in pulmonary arterial and wedge pressures, and pulmonary vascular resistance, without any significant change in heart rate, aortic pressure, or cardiac output. A fall in pulmonary arterial and left ventricular filling pressures is frequently observed with glyceryl trinitrate in patients with heart failure because of its significant venodilator effect (Mason and Braunwald, 1965; Miller et al., 1976). Thus, the 


\begin{tabular}{|c|c|c|c|c|c|c|c|c|c|c|c|c|c|c|}
\hline \multicolumn{3}{|c|}{$C O(l / \min )$} & \multicolumn{3}{|c|}{$S V(m l)$} & \multicolumn{3}{|c|}{$S V R$ (units) } & \multicolumn{3}{|c|}{$P V R$ (units) } & \multicolumn{3}{|c|}{$L V S W(g m)$} \\
\hline$C$ & $\boldsymbol{H}$ & $H+N$ & $C$ & $H$ & $H+N$ & $C$ & $H$ & $H+N$ & $C$ & $H$ & $H+N$ & $C$ & $H$ & $H+N$ \\
\hline $\begin{array}{l}1.75 \\
4.60 \\
3.50 \\
3.20 \\
6 \cdot 10 \\
2.50 \\
5.00 \\
5.00 \\
3.00 \\
3.85 \\
0.50\end{array}$ & $\begin{array}{l}3 \cdot 50 \\
6 \cdot 10 \\
4 \cdot 70 \\
4 \cdot 20 \\
6 \cdot 20 \\
5 \cdot 60 \\
6 \cdot 00 \\
7 \cdot 80 \\
4 \cdot 70 \\
5 \cdot 42 \\
0 \cdot 40\end{array}$ & $\begin{array}{l}4 \cdot 00 \\
5 \cdot 10 \\
4 \cdot 70 \\
4 \cdot 10 \\
5 \cdot 20 \\
5 \cdot 90 \\
7 \cdot 80 \\
4 \cdot 10 \\
5 \cdot 10 \\
0 \cdot 40\end{array}$ & $\begin{array}{r}21 \cdot 8 \\
51 \cdot 1 \\
41 \cdot 2 \\
50 \cdot 0 \\
70 \cdot 1 \\
33 \cdot 3 \\
60 \cdot 2 \\
47 \cdot 2 \\
29 \cdot 1 \\
44 \cdot 9 \\
5 \cdot 1\end{array}$ & $\begin{array}{r}46 \cdot 1 \\
63 \cdot 5 \\
58 \cdot 8 \\
58 \cdot 3 \\
68 \cdot 9 \\
71 \cdot 8 \\
68 \cdot 2 \\
77 \cdot 2 \\
47 \cdot 5 \\
62 \cdot 3 \\
3.5\end{array}$ & $\begin{array}{r}45.5 \\
52.0 \\
56.0 \\
60 \cdot 3 \\
56 \cdot 5 \\
64.1 \\
71 \cdot 6 \\
41.0 \\
55.9 \\
3.5\end{array}$ & $\begin{array}{r}49 \cdot 1 \\
14.3 \\
26.0 \\
31.6 \\
16.4 \\
20 \cdot 0 \\
12.2 \\
14.6 \\
31.7 \\
24.0 \\
3.8\end{array}$ & $\begin{array}{r}20.9 \\
10.7 \\
17.0 \\
22.1 \\
16.1 \\
15.5 \\
9.8 \\
10.0 \\
15.7 \\
15.4 \\
1.5\end{array}$ & $\begin{array}{r}16.8 \\
12.7 \\
15.3 \\
22 \cdot 7 \\
18.5 \\
\overline{10.2} \\
9.5 \\
18.3 \\
15.3 \\
1.6\end{array}$ & $\begin{array}{c}10.3 \\
4 \cdot 1 \\
1 \cdot 7 \\
3.1 \\
0.8 \\
3.6 \\
1.2 \\
4.0 \\
1.0 \\
3.3 \\
0.9\end{array}$ & $\begin{array}{l}2.9 \\
2.1 \\
0.9 \\
1.9 \\
1.1 \\
0.9 \\
1.2 \\
2.2 \\
0.6 \\
1.5 \\
0.3\end{array}$ & $\begin{array}{l}1.3 \\
2.2 \\
0.9 \\
2.0 \\
1.5 \\
1.4 \\
2.3 \\
0.7 \\
1.5 \\
0.2\end{array}$ & $\begin{array}{r}15 \cdot 4 \\
30.6 \\
34.2 \\
53.0 \\
82.0 \\
8.1 \\
32.7 \\
30.8 \\
31.6 \\
35.4 \\
7.2\end{array}$ & $\begin{array}{r}26 \cdot 3 \\
40 \cdot 6 \\
55 \cdot 1 \\
61 \cdot 1 \\
82 \cdot 4 \\
60 \cdot 1 \\
36 \cdot 2 \\
57 \cdot 8 \\
38 \cdot 1 \\
50 \cdot 9 \\
5 \cdot 7\end{array}$ & $\begin{array}{r}24 \cdot 1 \\
31 \cdot 1 \\
46 \cdot 4 \\
66 \cdot 4 \\
66 \cdot 1 \\
\frac{38 \cdot 4}{52 \cdot 6} \\
34 \cdot 0 \\
44 \cdot 9 \\
5 \cdot 6\end{array}$ \\
\hline 0.50 & \multicolumn{2}{|c|}{$\begin{array}{l}<0.01 \\
<0.01 \\
\text { NS }\end{array}$} & & \multicolumn{2}{|c|}{$\begin{array}{l}<0.01 \\
<0.01 \\
<0.05\end{array}$} & & \multicolumn{2}{|c|}{$\begin{array}{l}<0.05 \\
<0.05 \\
\text { NS }\end{array}$} & \multicolumn{3}{|c|}{$\begin{array}{l}<0.05 \\
<0.05 \\
\text { NS }\end{array}$} & \multicolumn{3}{|c|}{$\begin{array}{l}<0.05 \\
<0.05 \\
\text { NS }\end{array}$} \\
\hline
\end{tabular}

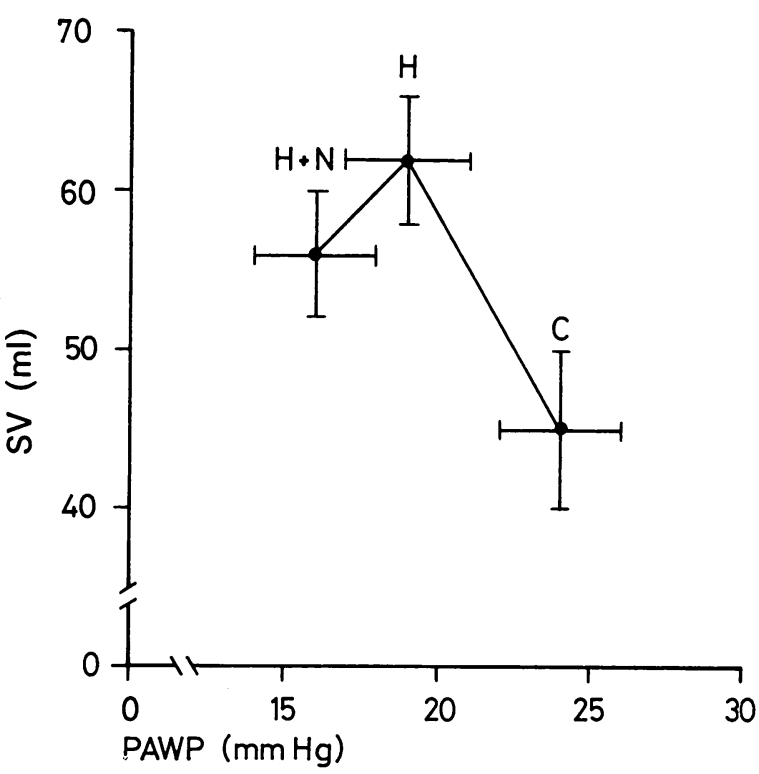

Fig. 3 Relation between stroke volume and mean pulmonary artery wedge pressure in patients with heart failure treated with hydrallazine alone and hydrallazine and glyceryl trinitrate combination. Abbreviations as in Fig 1 and 2.

combination of hydrallazine and glyceryl trinitrate paste results in haemodynamic effects identical to those of nitroprusside in heart failure. Whereas hydrallazine seems to have a major part in increasing cardiac output, glyceryl trinitrate primarily decreases pulmonary artery wedge and pulmonary arterial pressures (Fig. 3).

Our data suggest that a combination of oral hydrallazine and glyceryl trinitrate paste provides a non-parenteral regimen for reducing preload and afterload in some patients with heart failure in whom the symptoms of low cardiac output as well as high left ventricular filling pressure are present. However, in patients with predominant symptoms of low cardiac output, hydrallazine alone may be adequate. The peak response to hydrallazine therapy may take 48 to 72 hours to become apparent. No long-term trial with hydrallazine or other oral afterload reducing agents has yet been undertaken, but acutely hydrallazine appears to have a beneficial effect on symptoms. Though no major side effects were seen in this study, other investigators have reported occasional tachycardia and hypotension (Chatterjee et al., 1976; Franciosa et al., 1977). Caution is therefore necessary if large doses of hydrallazine are given to outpatients. The risk of developing a 'lupus-like syndrome' with high dose hydrallazine therapy (Perry, 1973) should also be kept in mind.

\section{References}

Ablad, B. (1963). A study of the mechanism of the hemodynamic effects of hydralazine in man. Acta Pharmacologica et Toxicologica, 20, Suppl. 1, p. 53.

Bolen, J. L., and Alderman, E. L. (1976). Hemodynamic consequences of afterload reduction in patients with chronic aortic regurgitation. Circulation, 53, 879-883.

Chatterjee, K., Parmley, W. W., Ganz, W., Forrester, J., Walinsky, P., Crexells, C., and Swan, H. I. C. (1973a). Hemodynamic and metabolic responses to vasodilator therapy in acute myocardial infarction. Circulation, 48, 1183-1193.

Chatterjee, K., Parmley, W. W., Swan, H. J. C., Berman, G., Forrester, J., and Marcus, H. S. (1973b). Beneficial effects of vasodilator agents in severe mitral regurgitation due to dysfunction of subvalvar apparatus. Circulation, 48, 684-690. 
Chatterjee, K., Parmley, W. W., Massie, B., Greenberg, B., Werner, J., Klausner, S., and Norman, A. (1976). Oral hydralazine therapy for chronic refractory heart failure. Circulation, 54, 879-883.

Cohn, J. N. (1973). Vasodilator therapy for heart failure. Circulation, 48, 5-8.

Franciosa, J. A., Guiha, N. H., Limas, C. J., Rodriguera, E., and Cohn, J. N. (1972). Improved left ventricular function during nitroprusside infusion in acute myocardial infarction. Lancet, 1, 650-654.

Franciosa, J. A., Mikulic, E., Cohn, J. N., Jose, E., and Fabie, H. (1974). Hemodynamic effects of orally administered isosorbide dinitrate in patients with congestive heart failure. Circulation, 50, 1020-1024.

Franciosa, J. A., Pierpont, G., and Cohn, J. N. (1977). Hemodynamic improvement after oral hydralazine in left ventricular failure. Annals of Internal Medicine, 86, 388-393.

Ganz, W., and Swan, H. J. C. (1972). Measurement of blood flow by thermodilution. American fournal of Cardiology, 29, 241-246.

Guiha, N. H., Cohn, J. N., Mikulic, E., Franciosa, J. A., and Limas, C. J. (1974). Treatment of refractory heart failure with infusion of nitroprusside. New England fournal of Medicine, 291, 587-592.

Khatri, I., Uemura, N., Notargiacomo, A., and Freis, E. D. (1977). Direct and reflex cardiostimulating effects of hydralazine. American fournal of Cardiology, 40, 38-42.

Koch-Weser, J. (1974). Myocardial inactivity of therapeutic concentrations of hydralazine and diazoxide. Experientia, 30, 170-171.

Majid, P. A., Sharma, B., and Taylor, S. H. (1971). Phenotolamine for vasodilator treatment for severe heart failure. Lancet, 2, 719-724.

Mantle, J. A., Russell, R. O., Jr., Moraski, R. E., and Rackley, C. E. (1976). Isosorbide dinitrate for the relief of severe heart failure after acute myocardial infarction. American fournal of Cardiology, 37, 263-268.
Mason, D. T., and Braunwald, E. (1965). The effects of nitroglycerin and amyl nitrite on arteriolar and venous tone in the human forearm. Circulation, 32, 756-766.

Mehta, J. (1977). Vasodilators in the treatment of heart failure. Fournal of the American Medical Association, 238, 2534-2536.

Miller, R. R., Vismara, L. A., Williams, D. O., Amsterdam, E. A., and Mason, D. T. (1976). Pharmacological mechanisms for ventricular unloading in clinical congestive heart failure: differential effects of nitroprusside, phentolamine and nitroglycerin on cardiac function and peripheral circulation. Circulation Research, 39, 127-133.

Moore-Jones, D., and Peroy, H. M., Jr. (1966). Radioautographic localization of hydralazine $-1-\mathrm{C}_{14}$ in arterial walls. Proceedings of the Society for Experimental Biology and Medicine, 122, 576-579.

Moyer, J. H. (1953). Hydrallazine (apresoline) hydrochloride: pharmacological observations and clinical results in the therapy of hypertension. Archives of Internal Medicine, 91, 419-439.

Perry, H. M., Jr. (1973). Late toxicity to hydralazine resembling systemic lupus erythematosus or rheumatoid arthritis. American Fournal of Medicine, 54, 58-72.

Rowe, G. G., Huston, J. M., Maxwell, G. M., Crossley, A. P., Jr., and Crumpton, C. W. (1955). Hemodynamic effects of 1 hydrazinophthalazine in patients with arterial hypertension. Fournal of Clinical Investigation, 34, 115-120.

Stunkard, A., Wertheimer, L., and Redisch, W. (1954). Studies on hydralazine: evidence for a peripheral site of action. Fournal of Clinical Investigation, 33, 1047-1053.

Requests for reprints to Dr J. Mehta, Box J-277 J.H.M. Health Center, University of Florida, Gainesville, Florida 32610, U.S.A. 